\title{
Science That Matters: The Importance of a Cultural Connection in Underrepresented Students' Science Pursuit
}

\author{
Matthew C. Jackson, ${ }^{+*}$ Gino Galvez, ${ }^{\dagger}$ Isidro Landa, ${ }^{\dagger}$ Paul Buonora, ${ }^{\ddagger}$ \\ and Dustin B. Thoman ${ }^{\S}$ \\ ${ }^{\dagger}$ Department of Psychology and "Department of Chemistry and Biochemistry, California State \\ University, Long Beach, Long Beach, CA 90840; "Department of Psychology, San Diego State \\ University, San Diego, CA 92182
}

\begin{abstract}
Recent research suggests that underrepresented minority (URM) college students, and especially first-generation URMs, may lose motivation to persist if they see science careers as unable to fulfill culturally relevant career goals. In the present study, we used a mixed-methods approach to explore patterns of motivation to pursue physical and life sciences across ethnic groups of freshman college students, as moderated by generational status. Results from a longitudinal survey $(N=249)$ demonstrated that freshman URM students who enter with a greater belief that science can be used to help their communities identified as scientists more strongly over time, but only among first-generation college students. Analysis of the survey data were consistent with content analysis of 11 transcripts from simultaneously conducted focus groups $(N=67)$; together, these studies reveal important differences in motivational characteristics both across and within ethnicity across educational generation status. First-generation URM students held the strongest prosocial values for pursuing a science major (e.g., giving back to the community). URM students broadly reported additional motivation to increase the status of their family (e.g., fulfilling aspirations for a better life). These findings demonstrate the importance of culturally connected career motives and for examining intersectional identities to understand science education choices and inform efforts to broaden participation.
\end{abstract}

Approximately 50\% of entering college students intending to major in physical and life sciences never obtain a science degree (National Center for Education Statistics [NCES], 2013, 2014). Though tempting for policy makers, searching for a monolithic solution to broadening participation aims is misguided, because empirical research demonstrates that the reasons why people lose the motivation to pursue science education differ considerably across groups of students. For example, even among the most well-prepared and highly achieving students, those from underrepresented minority (URM; i.e., black, Latino, and American Indian) backgrounds experience unique cultural barriers in science education that can contribute to a loss of motivation to persist in science (Hurtado et al.,1996; Seymour and Hewitt, 1997). URM students report experiencing negative campus climates that can generate a conflict between their cultural identities and science learning environments (Cole and Espinoza, 2008), and many URM students struggle to integrate their cultural identities with an emerging identity as a scientist (Chang et al., 2011; Tran et al., 2011). These students often do not see themselves as fitting their perceived images of scientists (Greenhalgh et al., 2004) and subsequently can lose interest in and disengage from science, typically switching to majors and career paths they perceive as more congruent with their cultural orientations. Even outside the science classroom, students' negative racial experiences can predict lower adjustment to college for high-achieving
Kenneth Gibbs, Monitoring Editor Submitted January 16, 2016; Revised June 10, 2016; Accepted June 10, 2016

CBE Life Sci Educ September 1, 2016 15:ar42 DOI:10.1187/cbe.16-01-0067

*Address correspondence to: Matthew C. Jackson (Matthew.jackson@csulb.edu).

(c) 2016 M. C. Jackson et al. CBE-Life Sciences Education @ 2016 The American Society for Cell Biology. This article is distributed by The American Society for Cell Biology under license from the author(s). It is available to the public under an Attribution-Noncommercial-Share Alike 3.0 Unported Creative Commons License (http://creativecommons.org/licenses/ by-nc-sa/3.0)

"ASCB $\circledR^{\circ}$ " and "The American Society for Cell Biology ${ }^{\circledR}$ " are registered trademarks of The American Society for Cell Biology. 
URM students, amplifying the lack of belonging that many URM students face (Smedley et al., 1993; Hurtado et al., 1996; Cabrera et al., 1999). Negative racial experiences are not exclusively experienced by URM students, and students from all groups who report negative racial experiences early in their collegiate careers tend to report a lower sense of belonging, seeing themselves as less of a part of their campus communities relative to their peers (Hurtado et al., 2007; Locks et al., 2008). However, in one sample, URM biomedical or behavioral science students who had such negative experiences early in their collegiate careers were shown to be more negatively impacted academically relative to their white or Asian peers (Hurtado et al., 2007). Negative racial experiences persist beyond the undergraduate years as well. Black and Latino scientists report unique frustrations, including being confused for janitorial staff rather than recognized as members of their scientific community, an experience not reported by their white and Asian peers (Bonilla, 2006; Williams and Dempsey, 2014). This can help explain why the attrition rate for URM students is higher than that of their peers (NCES, 2014). But what are the cultural barriers in science education, how do they take shape within science classrooms or curricula, and how can we create more inclusive environments that make science education more attractive and fulfilling for those who have been traditionally underrepresented?

One type of cultural barrier in science education results from negative competence stereotypes about one's group. Even if a student from a URM group does not directly experience overt discrimination, he or she is likely to face regular experiences with racial microaggressions (Sue et al., 2007, 2009), carry the burden of worrying that his or her performance will be judged through a stereotyped lens (Steele and Aronson, 1995; Chang et al., 2011), and feel uncertain about whether he or she can develop a sense of belonging in the science community (Darling et al., 2008; Chang et al., 2011; Tran et al., 2011). A voluminous body of research driven by stereotype threat theory (Steele, 1992, 1997)—which posits that the academic underperformance of underrepresented students can be partly explained by an anxiety caused by the fear that others' judgments of their actions will be perceived as confirming negative stereotypes about their group's intellectual ability-has documented this cultural barrier, explicated the processes that underlie it, and presented many solutions for how science education can lessen these effects. This work has become quite well-known and is now cited in virtually all national reports on broadening participation.

A second cultural barrier in science education, and the focus of our research, suggests that what makes science careers and science education attractive for students might differ across cultural backgrounds. A key consideration is the fit between the cultural values that exist (or are perceived to exist) within science and the culturally connected values of the groups who are traditionally underrepresented in science. In particular, prior research has illuminated the importance to URM students of altruistic or prosocial values of helping society or giving back to one's community. Whereas students from all backgrounds tend to highly value the traditional or stereotypical intrinsic reasons for pursuing science (e.g., curiosity, enjoyment of problem solving, passion for discovery), the career interests of URM students are also more likely to be influenced by prosocial cultural values than the career interests of their peers (Johnson, 2002; Thoman et al., 2015). Specifically, the reasons why URM students pursue certain careers, or what they hope to gain from their careers, is culturally influenced by a career purpose orientation that highly values contributing to society and giving back to the community through one's work. This research suggests that, when URM students fail to see connections between this prosocial orientation and what they are learning about science (and science careers), they are likely to experience greater incongruity between their cultural and science identities (Gibbs and Griffin, 2013; Thoman et al., 2015).

What we know about the role of prosocial values in shaping the development of career interest among science students comes primarily from studies of successful scientists, who had completed their $\mathrm{PhD}$ and were reflecting back on the reasons why they chose their current academic or nonacademic career path, and from advanced undergraduates, who were deciding their futures with the benefit of experience collaborating with faculty in laboratory research. However, URM students' transition and adjustment to college is most sensitive to campus cultural dynamics during the early undergraduate period (Hurtado et al., 2007). Thus, the current research examines how prosocial values shape the development of students' science identity and their interest in science careers just as they are beginning their undergraduate science education. Specifically, we examine how college freshmen's perceptions that science will allow them to meet goals of embodying prosocial values influences their development of science identity and career interest differently across cultural groups. This research contributes to a converging body of evidence emphasizing the importance of meeting prosocial goals to broadening participation in science education and careers.

\section{THE CULTURAL IMPORTANCE OF PROSOCIAL GOALS IN SCIENCE}

Students from all backgrounds value tasks and careers that afford opportunities to work with and/or help others (Sansone and Morgan, 1992; Isaac et al., 1999), but individuals from different cultural backgrounds place greater emphasis on these prosocial values than others. Previous research has documented the stronger prosocial orientation of ethnic minority groups that are underrepresented in science. For example, compared with white students, Latinos, African Americans, and American Indians place greater significance on the value of helping others through one's work, particularly giving back to one's community (Martin and Martin, 1985; Harper, 2005; Fryberg and Markus, 2007; Torres, 2009; Villarruel et al., 2009; Mohatt et al., 2011). Members of these cultural groups are more likely to emphasize participation in activities that benefit their ethnic community and making their community a priority (Martin and Martin, 1985; Torres, 2009).

Several recent survey and interview studies with advanced students or those who recently completed a $\mathrm{PhD}$ highlight the importance of prosocial values for URMs' choices to persist in science education. Tran and colleagues (2011) found that working for the purpose of creating social change is more highly valued by URM undergraduate students than well-represented (WR; i.e., white and Asian) students, both inside and outside science education contexts. Further, among URM students originally in a science-related field, meeting prosocial goals was more 
highly valued among those who chose to leave science than those who stayed. Interview data with science graduate students expanded these findings to suggest that URM students pursuing $\mathrm{PhD}$ and master's degrees experience a cultural conflict with regard to the relevance of science to social issues and, thus, a divergence between their cultural and science identities. Among those URM graduate students who maintained integration between their cultural and science identities, redefining science for themselves with a focus on community and justice emerged as a successful strategy for persistence (Tran et al., 2011).

A second set of surveys addressed to alumni from a program for URMs in biomedical science supported the importance of prosocial values in science career interest (Villarejo et al., 2008). These alumni rated what would make a career as a $\mathrm{PhD}$ researcher in science appealing for students. The two most highly rated attributes for these URM alumni were 1) satisfaction and interest in doing science and 2) knowing that scientific knowledge they created would help members of their community. Further, among these alumni who left the research career path, several cited "a desire to help others in a more direct manner" as a reason why they chose an alternative career path (Villarejo et al., 2008). These surveys highlight the retrospective importance of prosocial connections to the pursuit of science careers for URMs.

A third survey-here involving participants who had already obtained their PhDs in a biomedical field-investigated the role that personal values played in whether science $\mathrm{PhD}$ graduates chose academic versus nonacademic careers. Gibbs and Griffin (2013) found that, across groups, interest in pursuing faculty careers was driven by whether or not life as an academic scientist matched personal values. Specifically, if what an aspiring scientist felt was important to him or her personally and professionally could be best achieved in an academic setting, he or she was more likely to pursue a faculty career. However, URMs with a PhD were significantly more likely than those from WR ethnic groups to report having been motivated by the value they placed on the application of research to health problems specific to their communities. Further, PhDs from underrepresented groups uniquely reported feeling a responsibility to serve as role models in academia to combat the lack of representation that subsequent students would see of people who shared their underrepresented identity. URM PhDs who felt that the nature of faculty work would not allow sufficient engagement with such values were more likely to choose nonacademic career paths. Whereas individuals across groups reported less motivation to pursue science academically when they felt their work would not allow for practical application, URMs were uniquely affected by the realization that science would not allow them to work to impact their own communities. Importantly, when respondents felt that their prosocial goals could best be met in a science career, they were more likely to pursue a faculty career, despite acknowledgment of the great structural challenges (e.g., difficult job markets, low grant-funding rates, or high faculty workloads) to having a successful career in the biomedical workforce. This research demonstrated that all the way through the process of obtaining a $\mathrm{PhD}$, matching cultural values could be more important than differences in performance (i.e., number and average impact factor of publications), and negative experiences with mentors or structural challenges, in whether talented individuals chose to apply their skills outside their originally intended science domains (Gibbs and Griffin, 2013).

In addition to these interview and retrospective self-report studies, recent findings from a prospective longitudinal study of advanced undergraduates support similar conclusions (Thoman et al., 2015). Specifically, the longitudinal study explored research career motivation among students who had already demonstrated the competence to be accepted by faculty members as student researchers in biomedical faculty laboratories. Here, URM students-but not white students-who perceived that science could afford their prosocial goals of helping others and giving back to the community reported being more involved in their lab activities and, subsequently, a greater interest in a science career over time (Thoman et al., 2015). This research provided prospective evidence that cultural differences helped shape which personal values were influential in the development of science interest in advanced undergraduates. Owing to the cultural differences in what people look for in a career, helping students see how a science career can fulfill prosocial goals may remove barriers along the pathways into science careers, particularly for those groups who are most underrepresented in science.

\section{CONSIDERING IMPORTANT INTERSECTIONS BETWEEN SOCIAL IDENTITIES}

Each of the previously described studies highlights the importance of prosocial values in science for URM students. Empirical work in sociology, psychology, and education, however, suggests that, when examining college experiences of URM students, it is important to consider whether students come from families in which a parent has completed college or whether they are the first to attend college. Students who are the first in their family to attend college (first generation, FG) face unique challenges, such as less access to preparation for college expectations, relative to students who have at least one parent who graduated from college (continuing generation, CG). Perhaps, in part due to those challenges, attrition of FG college students occurs at nearly twice the rate of CG students (Chen, 2005; Radford et al., 2010). This alarming pattern has inspired several recent interventions to empirically test ways to reduce achievement gaps between FG and CG students (e.g., Smeding et al., 2013; Harackiewicz et al., 2014; Stephens et al., 2014). However, a review of such research noted that social class and ethnicity were often confounded in the subject populations, such that URMs were disproportionately overrepresented among FG students, making it difficult to disentangle the effects of ethnicity and FG status on student motivation and achievement (Harackiewicz et al., 2015). One exception examined FG status and ethnicity simultaneously, demonstrating that connecting students' personal values to science course work can be particularly helpful to FG-URM students, helping to close achievement gaps in undergraduate biology classroom performance. Harackiewicz and colleagues (2015) implemented classroom interventions for students taking introductory biology courses, asking the students to write essays about the personal relevance of their course material. While this exercise helped all students engage more deeply in their course work, this was especially true for FG-URM students. The intervention reduced achievement gaps for FG-URM students by $61 \%$ for the course (relative to CG students from WR backgrounds). To understand why the intervention boosted performance, the 
researchers conducted content analysis of the essays. Relative to a control condition, FG-URM students' essays about how the current science course was relevant to them personally contained more discussion of prosocial topics such as advising or encouraging others. FG-URM students were also significantly more likely to refer to their families. These data suggest that FG-URM science students may be especially oriented toward finding connections in their science course work that support their cultural values of helping their families and communities.

\section{OVERVIEW OF CURRENT STUDY}

Previous empirical work has examined the relationship between perceptions of the ability to meet prosocial goals and science attrition for URMs from the advanced undergraduate stage through completion of the $\mathrm{PhD}$. In the current study, we explore this relationship for first-semester college students-those who are just being introduced to science as a professional discipline. It is possible that those who are still just learning about the professional lives of scientists might not yet have formed an opinion on whether a career in science can meet prosocial goals. Alternatively, students may be more impacted by challenges to the notion that science can be used to meet prosocial goals before having concrete experiences in laboratories to develop their interest and motivation. A report from the U.S. Department of Education indicated that a failure to be engaged with rigorous and interesting science course work during one's freshman year is a greater predictor of a students' propensity to switch to another major than factors such as insufficient precollegiate preparation or overall academic performance (NCES, 2014). This finding was particularly strong among the highest-achieving students, suggesting that attending to students' early collegiate experiences may also be critical to retain the most highly qualified students in science fields.

Prior research addresses the concerns of those who have extended training and, frequently, a vision for what a specific career choice would entail (e.g., applying a specific research question to people from a particular community or mentoring a younger student from a similar background). However, less is known about role of personal or cultural value congruency among students just entering college, when much of the science attrition occurs. The present study was designed to address this gap in our understanding by engaging college freshmen about the role of their personal and cultural values in the development of their science identities and career interests. Through longitudinal surveys and a series of focus groups, we examined the role that prosocial values play in students' development of a science

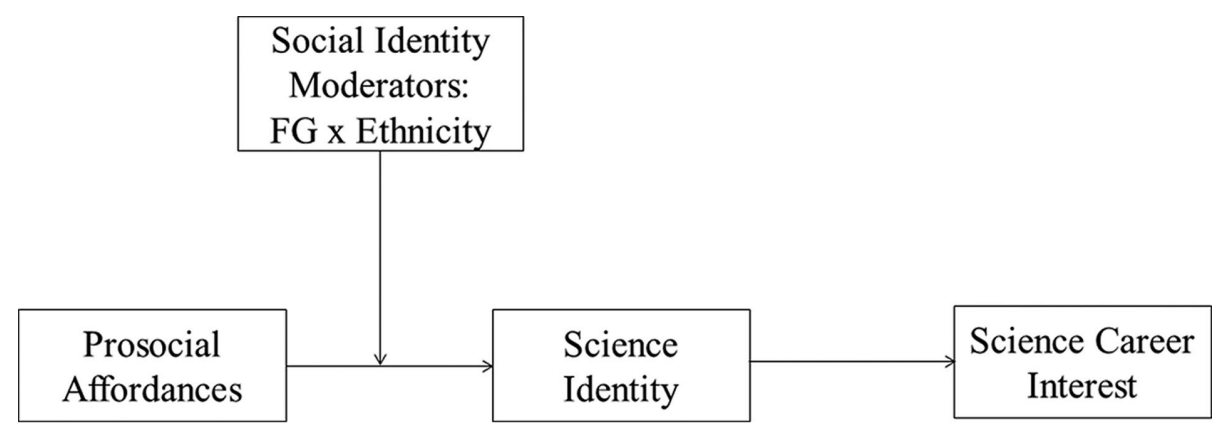

FIGURE 1. Conceptual model predicting future science career interest. identity and desire to pursue a career in science, with a specific focus on how the values that students hope to fulfill through science careers vary across ethnic identities. The present study asks: Does variability across students' perceptions of prosocial affordances in their initial college experiences predict greater science identity and interest in scientific careers? We test whether variability in early perceptions of prosocial affordances across physical and life sciences majors students within the first few weeks of college predicts end-of-semester science identity and career interest. We supplement this longitudinal survey with a qualitative examination of our freshman student population through a series of focus groups to gain a more nuanced understanding of URM students' initial perceptions of science, interest in science careers, and prosocial cultural orientations.

We predicted that URM students, and particularly FG-URMs, would develop stronger identities as scientists and greater interest in pursuing science research careers when they saw science as providing opportunities to meet their culturally connected prosocial goals, particularly benefiting their community (see Figure 1).

\section{SURVEY PHASE \\ Methods}

A longitudinal survey followed first-semester college freshmen planning to complete a science major across their first academic semester to test whether baseline perceptions that a science career would allow students to achieve their prosocial goals would predict their end-of-semester science identity and desire to pursue a career in science. This data collection was a part of broader study intended to identify the characteristics of URM students who persist in their science education. This broader survey administered several measures that are unrelated to the current research questions, including extensive demographic information (e.g., places of residence and upbringing, employment information, family size, and languages spoken) and surveys regarding students' social connections to scientists and science-related interactions with their family and friends. To answer the present research questions, we selected out only those variables with a priori theoretical connection to the role of cultural goals and barriers and one control variable that typically shows a strong empirical relationship with science career interest.

\section{Participants}

First-year college students majoring in science were recruited from a large 4-year public university in Southern California via email. The authors gained access to all members of the incoming freshman cohort with declared intentions to major in a field represented in the College of Natural Sciences and Mathematics. Potential participants received an email that advertised an opportunity to participate in a longitudinal study with the aim of "understanding and improving science education at the university." The response rate to the email was $45 \%$.

Participants were 249 first-semester freshman undergraduate students $(69 \%$ female; mean age $=18)$. Of 
these participants, 119 were classified as being from a URM group (82 Latinos, eight African Americans, four Pacific Islanders, one American Indian or Alaska Native, and 24 of mixed ethnicity including at least one of the URM groups), 70 were Asian, 40 were white, and 20 were of mixed ethnicity not including any of the URM groups. The participants included 116 students who classified themselves as FG college students (78 FG-URM; 63 Latinos, four African Americans, one Pacific Islander, and nine of mixed ethnicity including at least one of the URM groups). The ethnic diversity is representative of the population from which the sample was drawn, and due to the diverse nature of the university, no targeting of specific ethnic groups was necessary to obtain this demographic diversity.

\section{Procedure}

The analysis covered one academic semester. At time 1 (2-3 weeks into the Fall semester) all students completed an initial online survey that probed measures of beliefs about whether or not a career in science would afford (or fulfill) prosocial goals, a measure of how much students self-identified as scientists psychologically, and a measure of how interested the students were in having a career in science. Simple demographic information, including FG status and URM status (i.e., ethnicity) was also collected. The time 2 survey was administered 1 week after the conclusion of the semester ( 12 weeks later) and included the same measures as in time 1 . Two hundred and seven (90 URM) of the initially recruited students participated in the time 2 survey.

\section{Materials}

For measuring beliefs about whether or not a career in science would afford meeting prosocial goals, participants received the prompt: "Different people feel like they get different things from their work. Below is a list of some of these things. Please read each one, then indicate the extent to which a career working in science is likely to fulfill these things for you." Participants were then asked to rate their agreement (possible responses to each scale ranged from "1: Not at all" to "7: Very much") with the expectation that a career in science will allow them to: 1) "Make a contribution to society," and 2) "Give me an opportunity to be directly helpful to others," 3) "Do work that is worthwhile to society," and 4) "Give back to my community" ( $\alpha=0.72$; adapted from Johnson, 2002).

Participants completed a six-item scale measuring how strongly they identified with being a scientist ( $\alpha=0.88$ at time 1 , $\alpha=0.91$ at time 2; adapted from Chemers et al., 2011). Participants were asked to what extent they agreed with items such as the following samples: "I have come to think of myself as a scientist," and "I feel like I belong in the field of science." Students' desire to pursue a career in science was measured by asking them to complete a two-item measure that included the questions: "Could you see yourself building a career as a scientist?," and "How committed are you to a career in science?" ( $\alpha=0.77$ at time $1, \alpha=0.90$ at time 2; adapted from Chemers et al., 2011).

The survey also included a measure of students' performance expectations in science classes while entering college. Students reported their agreement with a single item: "I expect to do well in all of my science classes." This item was assessed as a covariate as described below (see Indirect Effects of Prosocial Affordance Perceptions on Career Interest via Science Identity).

\section{Data Preparation and Analysis}

We examined the correlations between early-semester (time 1) perceptions of science as affording students the ability to fulfill their prosocial goals and end-of-semester (time 2) science identity, while controlling for early-semester (time 1) science identity. By controlling for time 1 , we test the hypothesis that initial perceptions of science as affording students the ability to fulfill their prosocial goals can predict the development of science identity at the earliest stages of students' careers. We conducted partial correlations separately for each of four groups of students: FG-URM, CG-URM, FG-WR, and CG-WR. The data patterns for WR students were similar across groups (i.e., white and Asian students); we therefore aggregated across those students for the analyses of this study (for more on why one should be cautious in assuming that white and Asian students will follow similar patterns, see Focus Group Phase below).

We then used the computational tool PROCESS (Hayes, 2013) as an SPSS macro utility to estimate the indirect effects of prosocial affordances on career/graduate school interest via increased science identity for each group of students. The statistical model (PROCESS model 9) tests for moderated mediation, wherein science identity (at time 2) was predicted to mediate the effect of prosocial affordance (at time 1) on science career/ graduate school interest (at time 2) for FG-URM students, but not for CG-URM, FG-WR, or CG-WR students. The analysis model provides complete regression results for predicting the mediator (time 2 science identity) and the outcome (time 2 science career interest), controlling for time 1 perceived competence, time 1 science identity, and time 1 science career interest. For our predictions, which focus on a single group among the four, the critical test is the test for mediation (indirect effect) that is provided separately for each group.

\section{Results}

Baseline Profiles. Our student population had similar profiles entering freshman year (see Table 1 for means and SEs for each URM by generation intersection). No significant differences in science identity and career interest across URM and generation status (i.e., either main effects or interactions) were observed. There was a main effect of generation status on beliefs about whether or not a career in science would afford meeting prosocial goals $(F(1,231)=4.45, p=0.036)$, such that FG students $(\mathrm{M}=5.68, \mathrm{SE}=0.11)$ had a greater belief in the prosocial affordances of a science career, relative to CG students $(M=5.37$, $\mathrm{SE}=0.10$ ). There was no main effect of URM status and no interaction effect.

Partial Correlations. Partial-correlation data indicate that initial beliefs that science will allow students to meet prosocial goals significantly correlated with greater science identity at the end of the semester only for FG-URMs $(r(75)=0.31 p=0.016)$. There was not a significant partial correlation for CG-URMs $(r(34)=0.18, p=0.350)$, FG-WRs $(r(35)=-0.15, p=0.438)$, or CG-WRs $(r(89)=-0.11, p=0.390)$.

Similarly, we examined the correlations between early-semester (time 1) perceptions of science as affording students the ability to fulfill their prosocial goals and end-of-semester (time 2) desire to pursue a science career, while controlling for earlysemester (time 1) desire to pursue a science career. Partial-correlation data indicate that initial beliefs that science will allow 
TABLE 1. Profiles of freshman students (means and SEs) at time 1 and time 2, with generation by URM status intersections

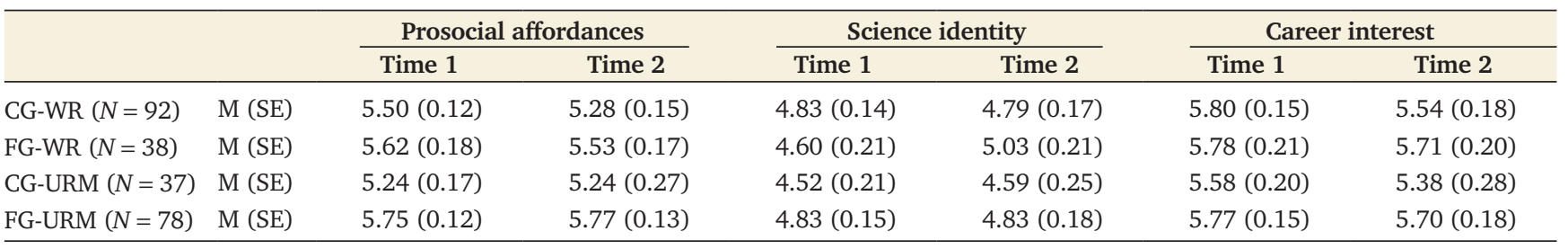

CG = continuing-generation college students; FG = first-generation college students; WR = well-represented ethnic group; URM = underrepresented ethnic group. None of the differences are statistically significant. All means are on a seven-point scale.

students to meet prosocial goals did not significantly correlate with greater science career interest at the end of the semester for FG-URMs $(r(75)=0.09, p=0.50)$. Nor was there a significant correlation for CG-URMs $(r(34)=-0.12, p=0.536)$, FG-WRs $(r(35)=0.02, p=0.914)$, or CG-WRs $(r(89)=-0.10, p=0.429)$.

End-of-semester (time 2) science identity and end-of-semester (time 2) desire to pursue a science career were positively correlated for each group: FG-URMs, $r(75)=0.61, p<0.001$; CG-URMs, $r(34)=0.63, p<0.001$; FG-WRs, $r(35)=0.67$, $p \leq 0.001$; and CG-WRs, $r(89)=0.80, p<0.001$.

Our theoretical model suggests that perceiving science as affording opportunities to fulfill culturally connected prosocial goals should increase science career interest for freshman FG-URM students, because it helps them develop a greater sense of identity as a scientist. This is consistent with previous research on advanced undergraduates participating in research labs, which found that perceived prosocial affordances of a career in science indirectly increased URM students' future science career interest through increased psychological engagement (Thoman et al., 2015). Therefore, we next examined this mediation prediction using regression analyses with bootstrapped indirect effects.

Indirect Effects of Prosocial Affordance Perceptions on Career Interest via Science Identity. Overall, the model predicted a statistically significant amount of variance in science identity $\left(R^{2}=0.46, F(7,185)=26.65, p<0.001\right)$ and career interest $\left(R^{2}=0.61, F(4,188)=73.81, p<0.001\right)$. For the critical test of our predictions, the indirect effect results demonstrate that a significant positive indirect effect of prosocial affordance on science career interest through science identity was found only for FG-URMs, as the 95\% bias-corrected bootstrap confidence interval (0.03-0.29) was greater than zero (see Table 2). For FG-URMs, perceiving science as more likely to afford prosocial goals predicted greater science identity, which in turn predicted greater

TABLE 2. Test of science identity as mediating the effect of initial perceptions of science affordances on interest in a career/graduate school in science for CG-WR, FG-WR, CG-URM, and FG-URM students

\begin{tabular}{lrrrc}
\hline & Effect & SE & CI low & CI high \\
\hline CG-WR & -0.041 & 0.060 & -0.212 & 0.045 \\
FG-WR & 0.010 & 0.089 & -0.156 & 0.201 \\
CG-URM & 0.097 & 0.089 & -0.071 & 0.289 \\
FG-URM & 0.148 & 0.064 & 0.031 & 0.290 \\
\hline
\end{tabular}

${ }^{\mathrm{a}} \mathrm{CI}$ low and $\mathrm{CI}$ high represent the range of the confidence interval for each generation by URM status intersection. interest in science careers at the end of the semester. For CG-URM (-0.07-0.28), FG-WR (-0.16-0.20), and CG-WR (-0.21-0.05) students, however, this indirect effect was not significant, as each 95\% bootstrap confidence interval contained zero.

Next, we tested the model again, this time controlling for students' performance expectations, because differences in performance expectations have been used to explain groupbased differences in interest (Lent et al., 1986; Lapan et al., 1996). Further, early class performance expectations are correlated with actual performance (grades), interest in classes, and subsequent interest in the field (Harackiewicz et al., 2000). Thus, it is important to demonstrate that effects of prosocial affordance perceptions are reliable above and beyond effects of performance expectations on motivation to persist in science. Controlling for performance expectations, the model still predicts a statistically significant amount of variance in science identity $\left(R^{2}=0.47, F(7,185)=20.68, p<0.001\right)$ and career interest $\left(R^{2}=0.62, F(4,188)=59.01, p<0.001\right)$. Again, a significant positive indirect effect of prosocial affordance on science career interest through science identity was found only for FG-URMs (95\% CI: 0.01-0.25), But not for any other group: CG-URMs, -0.14-0.24; FG-WRs, -0.13-0.24; and CG-WRs, -0.19-0.04.

\section{Conclusion}

These results indicate that, as early as freshman year, whether students see that science will allow them to fulfill prosocial goals can be more important for underrepresented students in science fields than for students who are traditionally well represented. As suggested by previous research (Harackiewicz et al., 2015), the intersections of social identities are important here as well. The moderating impact of ethnicity only held for FG college students. It is interesting to note that, while the correlation between the perceived prosocial affordances of science and science identity was not significant for CG-URM students, it trends in the same positive direction as for FG-URM students. Thus, it is important not to rule out the possibility that the perceived prosocial affordances of a science career can be important to all underrepresented students beyond the first semester of college, as has been found in previous research (e.g., Thoman et al., 2015). Rather, we argue that protecting such perceptions may be particularly important to FG-URM students at the beginning of their college careers.

While this provides evidence supporting the importance of considering both ethnicity and FG status when understanding student motivation and persistence, it provides a limited view into the different form that these motivations might take across groups. To better understand the different motivations 
expressed between cultural groups, we conducted focus groups with the ethnic groups with the largest populations on campus, including Latino, Asian, and white students (data collection and the survey study occurred simultaneously). In these focus groups, we probed students for the nuanced values that motivate their desire to pursue science.

\section{Limitations}

This survey is limited in that the data collection only spans the course of students' first semester of school. These data speak to the importance of being attentive to students' perceptions of the prosocial affordances of future science careers early in students' careers. However, further research is needed to determine how long throughout the course of students' academic careers such perceptions predict future career interest. The current study does not address these longer-term questions.

\section{FOCUS GROUP PHASE Methods}

A series of focus groups were conducted to gain a deeper understanding of URM and WR freshmen's initial perceptions of science, interest in science careers, and prosocial cultural orientations. Focus groups are an ideal methodology to generate nuanced domain-specific content and are particularly useful in identifying and understanding culturally specific knowledge and meaning that members of a group share (Hughes and DuMont, 1993; Suzuki et al., 1999).

\section{Participants}

Using the recruitment methodology from our survey, freshman students were recruited based on sex and ethnicity characteristics to create homogeneous groups (e.g., Latina female group; Asian male group), as recommended by Morgan and Krueger (1998). Sixty-seven students participated in 11 focus groups $(56 \%$ female; mean age $=18.3)$. Of these 67 participants, 31 self-identified as Latino (46\%), 23 as Asian (34\%), and 13 as white (19\%). The participants included 31 (46\%) students who classified themselves as FG college students. However, homogeneous groups of FG and CG students were not created for each gender and ethnicity intersection, and as expected, ethnicity and generation status were not independent. Among the WR groups, most identified as CG. Ten out of 13 white students identified as CG, and 16 out of 23 Asian students identified as CG. In contrast, among Latinos, most (21 out of 31 ) identified as FG. In exploring the contrasts between FG and CG students, we focused only on Latino students, for two reasons. First, only this group had large enough sample sizes of FG (21) and CG (10) students to draw meaningful comparisons. Second, in the survey data, the effect of prosocial affordances was found to predict future motivation and interest only for FG-URMs, and we were most interested in comparisons between FG-URMs and CG-URMs.

\section{Procedure}

Following participant sign-ins and introductions, the study purpose was described at the beginning of each focus group. Informed consent and confidentiality regarding the discussion and deidentification of data in the audio recording was explained in detail. Participants were compensated with a $\$ 50$ gift card immediately following the consent procedure. At the end of each focus group, participants completed a demographic questionnaire and were thanked for their participation.

Each focus group was moderated by an experienced $\mathrm{PhD}$ trained as a qualitative researcher (Latino/bilingual-bicultural) and a graduate student (Latino/bilingual-bicultural) using guidelines proposed by Morgan and Krueger (1998). Diagrams of the seating arrangements and notes were taken for each focus group by the graduate student comoderator with some note-taking assistance from other graduate student team members (one white female and one Latino male). The semistructured interview guide contained open-ended questions pertaining to science interest, precollege preparation, familial and cultural influences, and degree and career aspirations. Each group lasted $\sim 90$ min. The number of focus groups was determined by the saturation of data (e.g., data replication and redundancy in participant responses to main research questions). Constant comparative methods were used to determine saturation (Glaser, 1965).

\section{Data Preparation and Analysis}

Following transcription, the audio recordings were reviewed by the moderators (G.G. and I.L.) to ensure accuracy of transcription. Following procedures outlined for conventional and directed content analysis (Hsieh and Shannon, 2005), G.G. and I.L. analyzed the transcripts. Content analysis is a qualitative research method used to interpret meaning from the content of text data through the systematic process of coding and identifying themes or patterns (Hsieh and Shannon, 2005). The initial codes ("themes" or "ideas" in the text) were developed through debriefings and ongoing conversations about the data and while studying the data and literature. Then the codes were revised in meetings aimed specifically at developing codes across the 11 focus group transcripts. The refinement of codes helped to test developing themes within and across focus groups of different students and to record a wider range of the students' experiences in studying science. The transcripts were imported into NVivo qualitative data analysis software (QSR International, 2014) for coding and analysis (i.e., identifying key themes, patterns, ideas, and concepts within the text data). The coding was checked by I.L. to ensure that the code definitions were consistently applied across the transcripts and then categorized. Categorizing consists of a researcher selecting certain codes as having significance in explaining events or processes in the data (Charmaz, 2004). This process consisted of both searching for the presence and absence (i.e., negative cases) of key themes/concepts.

\section{Results}

A content analysis of the transcripts revealed several themes. For the purposes of this mixed-methods paper, a theme focused on students' sociocultural influences on their educational and career pursuits (with three subthemes) was selected due to the overlap with the survey findings. These subthemes are 1) role of cultural background, 2) broader prosocial goals, and 3) family-specific prosocial goals. While most subthemes came up in all of the focus groups (i.e., subtheme 1 was present in $73 \%$ of focus groups, subtheme 2 was present in $100 \%$ of focus groups, and subtheme 3 was present in $82 \%$ of focus groups; see Table 3), differences between students are noted in each subtheme section. Table 4 presents exemplar quotes from the students to illustrate the subthemes. 
TABLE 3. First-level coding of participants' statements regarding the three subthemes

\begin{tabular}{|c|c|c|c|c|c|c|}
\hline \multirow[b]{2}{*}{ Focus group } & \multirow[b]{2}{*}{ Sample size } & \multicolumn{2}{|c|}{ Education } & \multicolumn{3}{|c|}{ Themes $^{\mathrm{a}}$} \\
\hline & & FG & CG & $\begin{array}{l}\text { 1. Role of cultural } \\
\text { background }\end{array}$ & $\begin{array}{l}\text { 2. Broader prosocial } \\
\text { goals }\end{array}$ & $\begin{array}{l}\text { 3. Family-specific } \\
\text { prosocial goals }\end{array}$ \\
\hline Asian & 6 & 1 & 5 & $\mathrm{X}$ & $\mathrm{X}$ & $\mathrm{X}$ \\
\hline Asian & 10 & 5 & 5 & $\mathrm{X}$ & $\mathrm{X}$ & $\mathrm{X}$ \\
\hline Asian & 7 & 1 & 6 & $\mathrm{X}$ & $\mathrm{X}$ & \\
\hline Latino & 7 & 5 & 2 & $\mathrm{X}$ & $\mathrm{X}$ & $\mathrm{X}$ \\
\hline Latino & 6 & 2 & 4 & $X$ & $\mathrm{X}$ & $\mathrm{X}$ \\
\hline Latino & 7 & 5 & 2 & $\mathrm{X}$ & $\mathrm{X}$ & $\mathrm{X}$ \\
\hline Latino & 5 & 3 & 2 & $\mathrm{X}$ & $\mathrm{X}$ & $\mathrm{X}$ \\
\hline Latino & 6 & 6 & 0 & $\mathrm{X}$ & $\mathrm{X}$ & $\mathrm{X}$ \\
\hline White & 7 & 2 & 5 & & $\mathrm{X}$ & $\mathrm{X}$ \\
\hline White & 4 & 1 & 3 & & $\mathrm{X}$ & $\mathrm{X}$ \\
\hline White & 2 & 0 & 2 & & $\mathrm{X}$ & \\
\hline Total & 67 & 31 & 36 & & & \\
\hline
\end{tabular}

${ }^{\mathrm{a} X}$ indicates the presence of a subtheme in a particular focus group.

\section{Sociocultural Influences on Students' Educational and Career Pursuits}

Subtheme 1: Role of Cultural Background. The role of cultural background and values played a significant role in both Latino and Asian student's interest in pursuing a science career.
This theme was not present in any of the focus groups with white students, whereas it was present in all focus groups with Latino or Asian students. When asked whether culture or values played a role in their educational pursuits, 78\% of Asian and $77 \%$ of Latino students discussed the importance of family and

TABLE 4. Sociocultural influences on educational paths

\begin{tabular}{|c|c|}
\hline Theme & Exemplar quotes $^{\mathrm{a}}$ \\
\hline $\begin{array}{r}\text { Role of cultural } \\
\text { background }\end{array}$ & $\begin{array}{l}\text { [My mother] said "If I had the opportunities you had, I would take them. So don't waste them because you have } \\
\text { them." (Female, Latina, FG, 3) } \\
\text { I really feel like it wouldn't be just an achievement for me but my parents would be really proud. They have put in so } \\
\text { much effort for me. I have the resources they didn't have growing up in order for me to succeed. So that definitely } \\
\text { motivates me to get a degree. (Male, Latino, FG, 7) } \\
\text { I have the chance to make a better future for myself and if I don't do it, it would be like we did all this for nothing } \\
\text { because they struggled a lot. Both my parents were, they were born in Mexico, and actually my grandpa was the } \\
\text { first one to come over here. (Male, Latino, FG, 3) } \\
\text { For the females, it's not "Get an education to better yourself, but marry someone that's rich." For the guys, they put all } \\
\text { the support on the males to get them an education and the females have to use whatever they had. (Female, } \\
\text { Latina, FG, 6) }\end{array}$ \\
\hline $\begin{array}{l}\text { Broader prosocial } \\
\quad \text { goals }\end{array}$ & $\begin{array}{l}\text { I kind of have the same goal in giving back to the community and helping out others. I feel like, at least a dentist gives } \\
\text { people a lot more confidence if they fix someone's teeth. It is just satisfaction they get seeing that patients smile } \\
\text { when they walk out of the office. I think that is really satisfying as a career and it will motivate me to wake up } \\
\text { every day, to go to work and help others. (Male, Asian, FG, 5) } \\
\text { I think it's the whole reason [connection between career and giving back]. You put a lot of effort into going in to class } \\
\text { and finishing your homework and reading the chapter and paying attention in class because you want to give back } \\
\text { to society. (Female, white, FG, 9) } \\
\text { Well the career I am pursuing is education, so I know going into this ... it's not about the money as much with your } \\
\text { degree. I want to help others like others helped me. (Male, Asian, CG, 5) } \\
\text { I think it is important. It all goes back to the community. We are a society so therefore there is a community, it's not } \\
\text { just about yourself. It's about yourself and those around you. Essentially you are involved. (Male, Latino, FG, 10) }\end{array}$ \\
\hline $\begin{array}{l}\text { Family-specific } \\
\text { prosocial goals }\end{array}$ & $\begin{array}{l}\text { It [science education] will help because the great income will help my dad stop working so much. He works like three } \\
\text { jobs right now. Getting a civil engineering degree will help my family mostly. (Female, Latina, FG, 3) } \\
\text { My family are immigrants. And same as Ana in the sense that I am the only kid who wanted to go to a four year out of } \\
\text { my family ... I want to do good because I don't, in a way I appreciate everything my parents did for me, but I don't } \\
\text { want to live like that. I want to, how Juan said, support them. (Male, Latino, FG, 10) } \\
\text { Seeing as, are most of us Asian? Yeah? I think there's this whole concept from very traditional Asian families, you're } \\
\text { going to try and hopefully go into a job that will give you the financial stability for when you have a family or your } \\
\text { future life. I feel that was instilled in me at a very young age. (Male, Asian, CG, 5) } \\
\text { I think being financially stable for me because all my life I've been really poor. Being here and fighting to go to the } \\
\text { top, to get a good job, and to have a better life for my kids. (Female, Latina, FG, 6) }\end{array}$ \\
\hline
\end{tabular}

${ }^{\mathrm{a}}$ Numbers in parentheses refer to the focus group number (1-11). 
how it influenced their goals. Among the Latino students, $86 \%$ of FG students and $60 \%$ of CG students reported the influence of their cultural background. For example, an FG Latino male student noted, "I want to say it's based on values. More for me, family values. Neither of my parents went to college so they raised me and my younger brother to always want to pursue more education. They would always push us to get better grades and make sure that we did the best we could at school, so we could keep wanting to be in school and go further than they ever did." Students also viewed pursuing a science career as a means of making their families proud. For example, an Asian female said, "I feel because I'm the first in my family to go to college, I want to be a good role model to my little brother and I want to succeed in what I do to show him that he can do it too and make my family proud." And students talked about their roles in fulfilling their parents' aspirations for a better life in this country. These students reported feeling an obligation to their parents given the sacrifices their parents made (e.g., immigrating, working multiple jobs).

Parental support in pursuing an education was reported in most focus groups (91\%). These comments generally referred to the perception that parents are supportive of their children pursuing an education or career of their choosing. However, among Asian students, 43\% noted that their parents strongly encouraged specific science careers (e.g., doctor, pharmacist). These students may feel obligated to pursue a helping profession, because these are viewed by their families as being more stable, successful, and prestigious careers. In contrast, $23 \%$ of white students and only $3 \%$ of Latino students indicated that their parents expected them to pursue specific science careers.

Subtheme 2: Broader Prosocial Goals. Giving back to society was described in every focus group as one of the reasons for pursuing a science degree and career. Most Latino students $(87 \%)$ reported prosocial reasons for pursuing their careers. In contrast, rates were lower among Asian (65\%) and white students (54\%). Disaggregating across generational status, the majority of both FG (17 of $21 ; 81 \%$ ) and CG (10 of 10; 100\%) Latino students reported broader prosocial goals. Students that felt a strong need to give back reported various ways in which their intended career goals would benefit society. These examples varied from constructing bridges to discovering new cures for cancer. Comments made by Latino students on the importance of giving back to their community included examples of personal experiences with family members being hospitalized or managing chronic conditions. For example, an FG Latina female student whose sister passed away from lupus said, "Basically, I want to make an impact, like find better treatments for diseases like lupus or cancer ... I feel if I do that, I'll be helping in her in a way, because I'll be helping others like her." Their comments suggest that they experience both a desire to contribute to society and sense of responsibility to their community. For example, when asked whether giving back to the community was important, another FG Latina student said, "I think so, because that's the whole purpose of it. Having a job that you could be proud of and that's actually helping other people. Not just where you want to work and benefit yourself. When you're working to help others or a group, that's the whole point."
Subtheme 3: Family-Specific Prosocial Goals. The importance of students pursuing a science career to financially support their families was described in most focus groups $(82 \%)$. More specifically, 55\% of all Latino students, $26 \%$ of Asian students, and $15 \%$ of white students noted family-specific prosocial goals (e.g., financial stability, serving as a role model to siblings). Among the Latino students, $66 \%$ of FG students and $30 \%$ of CG students reported family-specific prosocial goals. Many of these students came from backgrounds in which their families experienced economic hardship. These students noted that they wanted to pursue a science degree and career because it would likely lead to stable, high-paying jobs that could financially support their immediate families and their own future families. An FG Latina female student said, "I want to make enough money to help my dad stop working because he's been working since he was little. So I guess my reason would be to make enough money for my parents." In general, student's comments indicated that they did not take issue with the expectation or obligation to financially support their families. Among all students, only 7\% expressed dissatisfaction with the pressure their families placed on them. These students stated that their families did not acknowledge their personal interests and the diversity of science careers that can provide financial stability. An FG Asian female student said, "I feel pressure because they always tell me, you should do this, you should do that.' I want to do what I want to do." Across all groups, students reported that they thought that educational pursuits in science would lead to careers that would provide financial stability.

Group Differences in Subtheme Endorsement. Across the 11 focus groups, patterns emerge in the endorsement of sociocultural educational influences for each ethnic group (see Table 3). The majority of Asian and Latino students reported their cultural values influencing their academic pursuits, whereas this theme was absent from all focus groups with white students. Conversely, the majority of students from each ethnic group endorsed the importance of prosocial goals in career choice. However, such goals were more prevalent for Latino students (87\%) relative to Asian (65\%) and white students (54\%). Finally, Latino students were the only group for whom the majority of students endorsed family-specific prosocial goals, and thus, the only group for whom the majority of students endorsed all three subthemes as influencing their educational choices.

\section{Conclusion}

Results suggest that nuanced differences exist between Latino, Asian, and white freshmen's reasons for pursuing a science education. Latino students reported a greater connection between broader prosocial goals and their reasons for pursuing a science degree or career. Further, FG Latino students were more likely to express unique symbolic goals, such as being the first to get a college degree in one's family as a means of raising the prestige of one's family as a whole. Latino students were more likely to value the ability to provide practical financial support to their parents. Comments from Latino and Asian students indicate that their cultural backgrounds and values also play a significant role in their interest in pursuing a science education, as it affords them the possibility of satisfying symbolic and practical goals related to their families. Such 
sentiments were also more likely to be expressed by FG Latino students, relative to CG Latino students. The findings suggest that Asian and Latino students pursue science careers as a means of making their families proud, improving their families' standing, and fulfilling their parents' aspirations for a better life. Importantly, FG Latino students were the only group to have the majority of participants mention all three subthemes, reflecting a more complex set of prosocial motivations for pursuing a science degree and career. This may help explain the results of our longitudinal survey, where early-college FG Latino students were more strongly impacted by perceptions of science as able to fulfill prosocial goals, relative to CG Latino students. Though almost all Latino students reported the importance of giving back to one's community with one's work in the focus groups (subtheme 2), for FG Latino students, a prosocial science career would fulfill a broader set of goals (i.e., subthemes 1 and 3).

\section{GENERAL DISCUSSION}

Our results demonstrate that students' perceptions that prosocial values of helping others and giving back to the community can be fulfilled by a career in science can lead many URM students to become more interested in such careers. This finding is consistent with research finding that advanced URM students who recognize that their research fulfills prosocial goals are more psychologically involved in their research, which in turn leads to greater interest in pursuing science research careers (Thoman et al., 2015). However, unlike previous research on prosocial goals and science motivation, the current research indicates that these perceptions of science may be more important to some URM subgroups relative to others and that effects on science identity plays a critical mediating role in this process.

The importance of students' science identity development in this process should not be surprising, given the findings that students from URM backgrounds often struggle to connect their personal/cultural and science identities (Chang et al., 2011; Tran et al., 2011). When science is seen as failing to provide opportunities to fulfill students' prosocial cultural values, misalignment is created between their identities. But when students, in particular FG-URMs, can see science as providing opportunities to fulfill their culturally connected prosocial goals, they should experience greater congruity between their personal/cultural and science identities. During a life period when identity formation is a major developmental goal (Erikson, 1959) and undergraduate students are committing to and switching majors frequently, finding ways to help diverse sets of students authentically identify more strongly with science is important for broadening and sustaining participation.

As previous intervention work suggests (Harackiewicz et al., 2015), intersections of social identities are important to consider as we strive to discover the best practices for diversifying and broadening participation in science education. Future interventions should consider addressing nuanced sets of motivators tailored to excite the diverse sets of underrepresented students who are at highest risk of attrition. Specifically, a better understanding of the subgroup differences between FG- and CG-URM students will assist retention of the broadest sets of students. Our qualitative focus group data contribute to that understanding by identifying additional symbolic (i.e., raising the status of one's family) and practical (i.e., providing financial support to one's family) concerns that FG-URM college students are motivated by when selecting their career paths.

This research contributes to the growing body of evidence showing that attending to ways in which science can help students embody their personal values is an important aspect of science education, but even more so for particular groups of students (Hulleman and Harackiewicz, 2009; Hulleman et al. 2010; Harackiewicz et al., 2014, 2015). Future work planning interventions to help students maintain their belief that science can, in fact, help them meet their goals should consider testing interventions that specifically address the ability to fulfill prosocial goals, comparing this effect against already successful general utility value interventions.

Future research should also compare historically underrepresented groups (i.e., blacks, Latinos, and American Indians) directly to see whether these patterns hold across these groups. One limitation of our research is that the URM sample is primarily Latino in the quantitative survey phase and exclusively Latino in the qualitative focus group phase. Previous research has shown that various cultural groups that are underrepresented face similar cultural barriers and, thus, might be expected to follow similar patterns. However, the present research does not test this hypothesis directly. More work is needed to help inform the retention efforts of science educators across underrepresented groups.

Regardless, science educators should consider highlighting how course material is applicable to helping one's community as a means of protecting students' initial interest in science careers. Whereas this might be more likely to occur in advanced or specialized undergraduate courses, our findings suggest that broadening the possible definitions of what science is and what science pursuits can afford matters, even for first-semester freshmen. To fulfill the commitment expressed at the national level by national agencies such as the National Science Foundation (NSF) and National Institutes of Health and professional scientific societies, we must use what we have learned about why students pursue science and integrate this wisdom in our everyday teaching strategies.

As we move forward, it may become increasingly important to engage URM students about the opportunities to use science to meet prosocial goals from the very beginning of students' college experience (if not sooner). Interviews with URM scientists who have chosen against academic careers indicate that they are questioning the direct relevance of their pursuit of science (Gibbs and Griffin, 2013). These considerations are occurring in a broader context wherein culturally relevant social issues (e.g., racial disparities in police use of force, criminal sentencing, or immigration policy) have become part of our everyday conversations with violent urgency. Many URM aspiring scientists feel confronted with the question of the prosocial importance of channeling their passion into intellectual pursuits relative to redirecting that energy toward activism. To ensure continued progress in broadening participation in science fields, we must emphasize to young students how science will allow them to make significant contributions to society and not just find significant statistical results. 


\section{ACKNOWLEDGMENTS}

Data collected for this study and preparation of this article were supported in part by grant DRL-1420271 from the NSF. Any opinions, findings, and conclusions or recommendations expressed in this material are our own and do not necessarily reflect the views of the NSF.

\section{REFERENCES}

Bonilla J (2006). "Are you here to move the piano?": a Latino reflects on twenty years in the academy. In: Faculty of Color: Teaching in Predominantly White Colleges and Universities, ed. C Stanley, New York: Anker 68-79.

Cabrera AF, Nora A, Terenzini PT, Pascarella E, Hagedorn LS (1999). Campus racial climate and the adjustment of students to college. J High Educ 70, 134-160.

Chang MJ, Eagan MK, Lin MH, Hurtado S (2011). Considering the impact of racial stigmas and science identity: persistence among biomedical and behavioral science aspirants. J High Educ 82, 564-596.

Charmaz K (2004). Grounded theory. In: Approaches to Qualitative Research: A Reader on Theory and Practice, ed. SN Nagy Hesse-Biber and P Leavy, New York: Oxford University Press, 496-521.

Chemers MM, Zurbriggen EL, Syed M, Goza BK, Bearman S (2011). The role of efficacy and identity in science career commitment among underrepresented minority students. J Soc Issues 67, 469-491.

Chen X (2005). First-Generation Students in Postsecondary Education: A Look at Their College Transcripts (NCES 2005-171), Washington, DC. http://ncesedgov/pubs2005/2005171pdf (accessed 15 January 2016).

Cole D, Espinoza A (2008). Examining the academic success of Latino students in science technology engineering and mathematics (STEM) majors. J Coll Stud Dev 49, 285-300.

Darling E, Molina K, Sanders M, Lee F, Zhao Y (2008). Belonging and achieving the role of identity integration. In: Advances in Motivation and Achievement: Social Psychological Perspectives, ed. M Maehr, S Karabenick, and T Urdan, New York: Elsevier, 241-274.

Erikson EH (1959). Identity and the Life Cycle, New York: International Universities Press.

Fryberg SA, Markus HR (2007). Cultural models of education in American Indian, Asian American and European contexts. Soc Psychol Educ 10, $213-246$.

Gibbs KD, Griffin KA (2013). What do I want to be with my PhD? The roles of personal values and structural dynamics in shaping the career interests of recent biomedical science PhD graduates. CBE Life Sci Educ 12 $711-723$.

Glaser BG (1965). The constant comparative method of qualitative analysis. Soc Problems 12, 436-445.

Greenhalgh T, Seyan K, Boynton P (2004). "Not a university type": focus group study of social class, ethnic, and sex differences in school pupils' perceptions about medical school. Br Med J 328, 1541-1547.

Harackiewicz JM, Barron KE, Tauer JM, Carter SM, Elliot AJ (2000). Shortterm and long-term consequences of achievement goals: predicting interest and performance over time. J Educ Psychol 92, 316

Harackiewicz JM, Canning EA, Tibbetts Y, Giffen CJ, Blair SS, Rouse DI, Hyde JS (2014). Closing the social class achievement gap for first-generation students in undergraduate biology. J Educ Psychol 106, 375-389.

Harackiewicz JM, Canning EA, Tibbetts Y, Priniski SJ, Hyde JS (2015). Closing achievement gaps with a utility-value intervention: disentangling race and social class. J Pers Soc Psychol, doi: 10.1037/pspp0000075.

Harper SR (2005). Leading the way: Inside the experiences of high-achieving African American male students. About Campus 10, 8-15.

Hayes AF (2013). Introduction to Mediation Moderation and Conditional Process Analysis: A Regression-Based Approach, New York: Guilford

Hsieh HF, Shannon SE (2005). Three approaches to qualitative content analysis. Qual Health Res 15, 1277-1288.

Hughes D, DuMont K (1993). Using focus groups to facilitate culturally anchored research. Am J Community Psychol 21, 775-806.
Hulleman CS, Godes O, Hendricks BL, Harackiewicz JM (2010). Enhancing interest and performance with a utility value intervention. J Educ Psychol $102,880-895$

Hulleman CS, Harackiewicz JM (2009). Promoting interest and performance in high school science classes. Science 326, 1410-1412.

Hurtado S, Carter DF, Spuler A (1996). Latino student transition to college: assessing difficulties and factors in successful college adjustment. Res High Educ 37, 135-157.

Hurtado S, Han JC, Sáenz VB, Espinosa LL, Cabrera NL, Cerna OS (2007) Predicting transition and adjustment to college: biomedical and behavioral science aspirants' and minority students' first year of college. Res High Educ 48, 841-887.

Isaac JD, Sansone C, Smith JL (1999). Other people as a source of interest in an activity. J Exp Soc Psychol 35, 239-265.

Johnson MK (2002). Social origins, adolescent experiences, and work value trajectories during the transition to adulthood. Soc Forces 80, 1307-1341.

Lapan RT, Shaughnessy P, Boggs K (1996). Efficacy expectations and vocational interests as mediators between sex and choice of math/science college majors: a longitudinal study. J Vocat Behav 49, 277-291.

Lent R, Brown SD, Larkin KC (1986). Self-efficacy in the prediction of academic performance and perceived career options. J Couns Psychol 33, 265-269.

Locks AM, Hurtado S, Bowman NA, Oseguera L (2008). Extending notions of campus climate and diversity to students' transition to college. Rev High Educ 31, 257-285

Martin JE, Martin EP (1985). The Helping Tradition in the Black Family and Community, Silver Spring, MD: National Association of Social Workers Press.

Mohatt NV, Fok CCT, Burkey R, Henry D, Allen J (2011). Assessment of awareness of connectedness as a culturally-based protective factor for Alaska native youth. Cultur Divers Ethnic Minor Psychol 17, 444-455.

Morgan DL, Krueger RA (1998). The Focus Group Kit, Vols. 1-6, Thousand Oaks, CA: Sage.

National Center for Education Statistics (NCES) (2013). STEM in Postsecondary Education: Entrance, Attrition, and Coursetaking among 2003-04 Beginning Postsecondary Students (NCES 2013-152), Washington, DC http://nces.ed.gov/pubs2013/2013152.pdf (accessed 1 September 2016)

NCES (2014). STEM Attrition: College Students' Paths Into and Out of STEM Fields (NCES 2014-001), Washington, DC. http://nces.ed.gov/pubs2014/ 2014001rev.pdf (accessed 1 September 2016).

QSR International (2014). NVivo Qualitative Data Analysis Software, version 10, Burlington, MA

Radford AW, Berkner L, Wheeless SC, Shepherd B (2010). Persistence and Attainment of 2003-04 Beginning Postsecondary Students: After 6 Years (NCES 2011-151), Washington, DC: National Center for Education Statistics. http://ncesedgov/pubsearch (accessed 1 September 2016).

Sansone C, Morgan C (1992). Intrinsic motivation and education: competence in context. Motiv Emotion 16, 249-269.

Seymour E, Hewitt NM (1997). Talking about Leaving: Why Undergraduates Leave the Sciences, Boulder, CO: Westview.

Smeding A, Dumas F, Loose F, Régner I (2013). Order of administration of math and verbal tests: an ecological intervention to reduce stereotype threat on girls' math performance. J Educ Psychol 105, 850-860.

Smedley BD, Myers HF, Harrell SP (1993). Minority-status stresses and the college adjustment of ethnic minority freshmen. J High Educ 64, 434-452.

Steele CM (1992). Race and the schooling of black Americans. Atlantic Monthly 269, 468-78

Steele CM (1997). A threat in the air: how stereotypes shape intellectual identity and performance. Am Psychol 52, 613-629.

Steele CM, Aronson J (1995). Stereotype threat and the intellectual test performance of African Americans. J Pers Soc Psychol 69, 797-811.

Stephens NM, Hamedani MG, Destin M (2014). Closing the social-class achievement gap: a difference-education intervention improves first-generation students' academic performance and all students' college transition. Psychol Sci 25, 943-953.

Sue DW, Capodilupo CM, Torino GC, Bucceri JM, Holder AMB, Nadal KL, Esquilin ME (2007). Racial microaggressions in everyday life: implications for clinical practice. Am Psychol 62, 271-286. 
Sue DW, Lin Al, Tornio GC, Capodilupo CM, Rivera D (2009). Racial microaggressions and difficult dialogues on race in the classroom. Cultur Divers Ethnic Minor Psychol 15, 183-190.

Suzuki LA, Prendes-Lintel M, Wertlieb L, Stallings A (1999). Exploring multicultural issues using qualitative methods. In: Using Qualitative Methods in Psychology, ed. M Kopala and LA Suzuki, Thousand Oaks, CA: Sage, 123-134.

Thoman DB, Brown ER, Mason AZ, Harmsen AG, Smith JL (2015). The role of prosocial values in motivating underrepresented minority students for biomedicine. BioScience 65, 183-188.

Torres L (2009). Latino definitions of success: a cultural model of intercultural competence. Hisp J Behav Sci 31, 576-593.
Tran M, Herrera F, Garibay J (2011). When science lacks diversity and social relevance can students be objective scientists and still be themselves? Paper presented at the annual meeting of the National Conference on Race and Ethnicity in American Higher Education, held May 31-June 4 in San Francisco, CA.

Villarejo M, Barlow AE, Kogan D, Veazey BD, Sweeney JK (2008). Encourag ing minority undergraduates to choose science careers: career path survey results. CBE Life Sci Educ 7, 394-409.

Villarruel FA, Carlo G, Grau JM, Azmitia M, Cabrera NJ, Chahin TJ (eds.) (2009). Handbook of U.S. Latino Psychology: Developmental and Community-Based Perspectives, Thousand Oaks, CA: Sage.

Williams JC, Dempsey R (2014). What Works for Women at Work: Four Patterns Working Women Need to Know, New York: New York University Press. 